\title{
Informal payments for modern family planning methods at public facilities in Tanzania: room for improvement
}

\author{
Clara E. Busse ${ }^{1,2}$, Dickens Onyango $3,4,5^{*}$ (D) and Katherine Tumlinson ${ }^{1,2}$
}

\begin{abstract}
Background: Financial access to family planning (FP) is essential to the health and well-being of women in Tanzania. Tanzanian policy dictates that FP methods and services obtained at public facilities are provided for free. However, public sector FP is no longer free when providers solicit informal payments. In this analysis, we investigate the prevalence and amount of informal payments for FP in Tanzania.

Methods: We used data from the 2015-2016 Tanzania Demographic and Health Survey to investigate whether informal payments for FP had been effectively eliminated by this policy.

Results: We found that, at public sector facilities, the majority (84.6\%) of women received their current FP method for free (95\% confidence interval (Cl): $81.9,87.3)$, but this proportion varied meaningfully by facility and method type. Injectable contraception was the most commonly used method by women in the lowest wealth quintiles and was most frequently sought by these women from a government dispensary. One in four women (25.8\%) seeking injectable contraception from government dispensaries reported paying a fee $(95 \% \mathrm{Cl}: 19.5,32.1)$. Among injectable users who reported payment for their current method, the mean cost at public sector facilities was 1420 Tanzanian Shillings (TSh) and the mean cost at private sector facilities was TSh 1930 (approximately 0.61 United States Dollars (USD) and 0.83 USD, respectively). Among implant users who reported payment for their current method, the mean cost at public sector facilities was TSh 4127 and the mean cost at private sector facilities was TSh 6194 (approximately 1.78 USD and 2.68 USD, respectively).

Conclusion: These findings suggest that the majority of women visiting public facilities in Tanzania did not pay informal payments for FP methods or services; however, informal payments at public facilities did occur, varying by facility and method type. Adherence to existing policies mandating free FP methods and services at public facilities, especially government dispensaries, is critical for ensuring contraceptive access among the most economically vulnerable women.
\end{abstract}

Keywords: Informal payments, Informal fees, Contraception, Family planning, Quality-of-care, Access

*Correspondence: macdickens2002@gmail.com

3 Kisumu County Department of Health, P.O. BOX 3670, Kisumu 40100, Kenya

Full list of author information is available at the end of the article

\section{Background}

Access to high-quality family planning (FP) services is essential for the empowerment of women and girls and an important strategy for the reduction of poverty and maternal and child mortality [1]. Effective, voluntary FP allows women and girls to prevent unintended pregnancies and space their births to protect their health and the health of their children. FP may also increase a woman's original author(s) and the source, provide a link to the Creative Commons licence, and indicate if changes were made. The images or other third party material in this article are included in the article's Creative Commons licence, unless indicated otherwise in a credit line to the material. If material is not included in the article's Creative Commons licence and your intended use is not permitted by statutory regulation or exceeds the permitted use, you will need to obtain permission directly from the copyright holder. To view a copy of this licence, visit http://creativecommons.org/licenses/by/4.0/. The Creative Commons Public Domain Dedication waiver (http://creativeco mmons.org/publicdomain/zero/1.0/) applies to the data made available in this article, unless otherwise stated in a credit line to the data. 
autonomy in the home and improve her earning power and economic security [2]. Globally, $62 \%$ of married women ages 15 to 49 use a FP method, with $34 \%$ of this demographic using a FP method in low-income countries and $64 \%$ using a FP method in middle-income countries [3]. In sub-Saharan Africa, 34\% of married women ages 15 to 49 use a FP method and $29 \%$ use a modern method [3]. Tanzania has a contraceptive prevalence rate among married women of $38 \%$ and there has been small but consistent rise in FP use in Tanzania over the last decade, yet disparities in FP use by sociodemographic characteristics make those who are least educated, poorest, and unmarried and sexually active especially vulnerable to unintended pregnancy $[4,5]$. Thus, additional attention is needed to remove FP barriers for those women most vulnerable to the negative outcomes of an unintended pregnancy.

In Tanzania, known barriers to FP use include partner disapproval, limited healthcare access, myths and misinformation about FP, and concerns about costs of FP methods and services [6]. To ensure that cost is not a barrier to FP use, the Tanzanian Ministry of Health has mandated that FP services and methods are provided for free at all public facilities in Tanzania [6, 7]. At private sector facilities, clients may be charged a fee for the FP method and/or consultation [7]. However, research regarding informal payments made by FP clients in other sub-Saharan countries indicates that policies designed to ensure free contraceptive access do not always translate into practice. For example, despite policies enacted in 2013 that establish the provision of free FP at public facilities in Kenya, an analysis of 2014 Kenya Demographic and Health Survey (DHS) data by Radovich and colleagues found that only half of FP users who visited a public facility obtained their FP method for free at their most recent visit [8-11].

In fact, informal payments, defined as payments made by patients to healthcare providers that exceed the official cost of supplies or services, are common in a variety of healthcare settings in many low- and middle-income countries (LMICs) and informal payments often comprise a substantial share of healthcare spending in these contexts [12, 13]. Informal payments may take many forms, including charging for services that are supposed to be provided for free, pretending that there is a shortage of supplies and soliciting payments to obtain supplies, and requiring payments for higher quality care [13-17]. Informal payments may be solicited by health providers, but they may also be offered by patients as a demonstration of gratitude or as a method for receiving better care [16]. A study using focus groups of healthcare workers in Tanzania found that healthcare workers at all levels of care received informal payments through a variety of mechanisms [16]. Healthcare workers in this study reported that providers who gave their patients high-quality care were assumed to be receiving informal payments from them; for this reason, healthcare workers might be incentivized to reduce the quality of their health services to avoid being seen as corrupt [16]. Structural issues, such as low salaries of healthcare workers in public facilities, are thought to play a role in the system of informal payments in LMICs [14]. Despite their prevalence in LMICs broadly, the extent to which informal payments are leveraged for FP services is a gap in the current literature [18].

DHS and FP2020 data on the cost of current contraceptive methods are available for very few countries, but these data were collected in the Tanzania 2015-2016 DHS. Because informal payments for FP have the potential to prevent highly motivated women from obtaining their desired FP method, payments for FP at public sector facilities in Tanzania should be rigorously studied to ensure that existing policies are being effectively implemented.

To address this need, we used the Tanzania 2015-2016 DHS to describe the types and sources of FP methods and to characterize the prevalence and amount of informal payments. The Tanzania 2015-2016 DHS asked current users of an intrauterine device (IUD), injectable, implant, pill, and male condom, where they obtained their method, if they paid for their current FP method, and if so, how much. Using this existing data source, we investigated the extent to which informal payments in public sector facilities remain a barrier to FP provision in Tanzania. This paper is broadly modeled after Radovich and colleagues' 2019 analysis to allow for comparison between Kenya and Tanzania [10].

\section{Methods}

\section{Data source}

We used data from the Tanzania DHS (2015-2016), a nationally representative, cross-sectional household survey with a two-stage cluster sampling design $[19,20]$. Using this sampling strategy, 13,360 households were selected for the survey, of which 12,563 were occupied and completed the interview (98\% response rate). In the interviewed households, 13,634 eligible women (age 15-49) were identified for individual interviews using the Woman's Questionnaire, of which 13,266 women completed the interview (97\% response rate). The Woman's Questionnaire includes questions about the woman's use of modern contraceptives, the source of the method, and the amount paid for it. The DHS report provides additional details about the sampling procedure, data collection, and specific interview questions [5]. 
We analyzed data for women who self-reported currently using a modern contraceptive [10]. Due to small sample sizes, we excluded those using male sterilization $(n=3)$, female condom $(n=2)$, emergency contraception $(n=3)$, the DHS FP method category "other modern method" $(n=1)$, and the Standard Days Method $(n=2)$.

\section{Variables}

In Tanzania, FP is provided at a variety of facility types, which range in size from large hospitals, to mediumsized health centers, to small dispensaries, all of which are found in both the private and public sector. To capture this variation in facility types, we grouped women's self-reported most recent source of modern FP method into seven categories: government hospital, government health center, government dispensary, private facility (including private hospital/clinic, private nursing/maternity home), non-governmental organization/faith-based facility, pharmacy/chemist, and other (including shop, mobile clinic, friend/relative, other, community health worker, community-based distributor, other private medical) [10]. We considered the first three categories to be public sector (government-provided services) and the latter four categories to be private sector $[7,10]$. We excluded observations with missing data for most recent source of modern FP method ( $n=37)$.

The Tanzania 2015-2016 DHS did not collect cost data for all types of methods. Therefore, to analyze informal payments, we limited this analysis to women who selfreported currently using a modern contraceptive method for which data on price were collected; this included the IUD, injectable, implant, pill, and male condom. Observations with missing values for informal payments were removed $(n=145)$. One woman responded with "do not know" for informal payments amount and was excluded. Self-reported payment values were inspected for improbable values. No values were found to be greater than 10 times the 95th percentile, the criterion specified for improbable values by Radovich and colleagues [10].

Several sociodemographic characteristics were included in our analysis. Quintile of household wealth was determined by the DHS based on measures of household assets appropriate for the Tanzanian context. Highest level of educational attainment was categorized as no education, primary, and secondary or higher. Due to sample size limitations, binary age was used, categorized as less than 30 years and 30 or more years.

\section{Analysis}

Three main variables were of interest in our analysis: modern FP method, source of modern FP method, and payment for modern FP method. Payment for modern FP method was measured using two questions: (1) "Did you pay for (CURRENT METHOD)?"; (2) "How much did you pay for (CURRENT METHOD)?" [5]. We described modern contraceptive method mix by wealth quintile and source of FP. Injectable and implant use was reported by wealth quintile and source of FP. We then analyzed the proportion of modern contraceptive users reporting free FP planning by public sector facility type. Finally, we characterized the amount paid for current method among injectable and implant users who reported a nonzero payment for their current method at a public sector facility. Portions of our analysis (Fig. 3; Table 2) were limited to injectables and implants, as these were the only methods dispensed as a single unit and for which there was a sample size of at least 30 participants with non-zero payment for their current method, once stratified by facility type. Self-reported informal payments for FP method among injectable and implant users was reported in Tanzanian Shillings (TSh), with one USD being equal to approximately TSh 2300. Analyses were conducted in SAS version 9.4 (SAS Institute, Inc., Cary, North Carolina).

\section{Results}

Modern contraceptive users with data for source of method available were included in our analytic sample (unweighted $n=3197$ ). We found that the majority of women visiting public facilities in Tanzania did not pay informal payments for FP methods or services; however, informal payments at public facilities did occur, varying by facility and method type.

\section{Method mix}

The mix of modern methods was fairly consistent across the four poorest wealth quintiles, with injections accounting for the largest share of use, followed by implants, and then the pill (Fig. 1). Male condoms increased in use with increasing wealth and accounted for less than $10 \%$ of use among the three poorest quintiles, but over one quarter of use among the richest. In the richest quintile, injectables were as common as male condoms and the pill and implants accounted for less than one fifth of methods each. Female sterilizations did not vary substantially by wealth quintile. Use of IUDs and the Lactational Amenorrhea Method (LAM) was uncommon across all wealth quintiles.

\section{Method source}

Women sourced FP methods from a variety of facility types. Public facilities, including government hospitals, government health centers, and government dispensaries served as the source for the majority (ranging from approximately $60 \%$ in the richer quintile to over $75 \%$ in the poorest quintile) of current modern contraceptive 


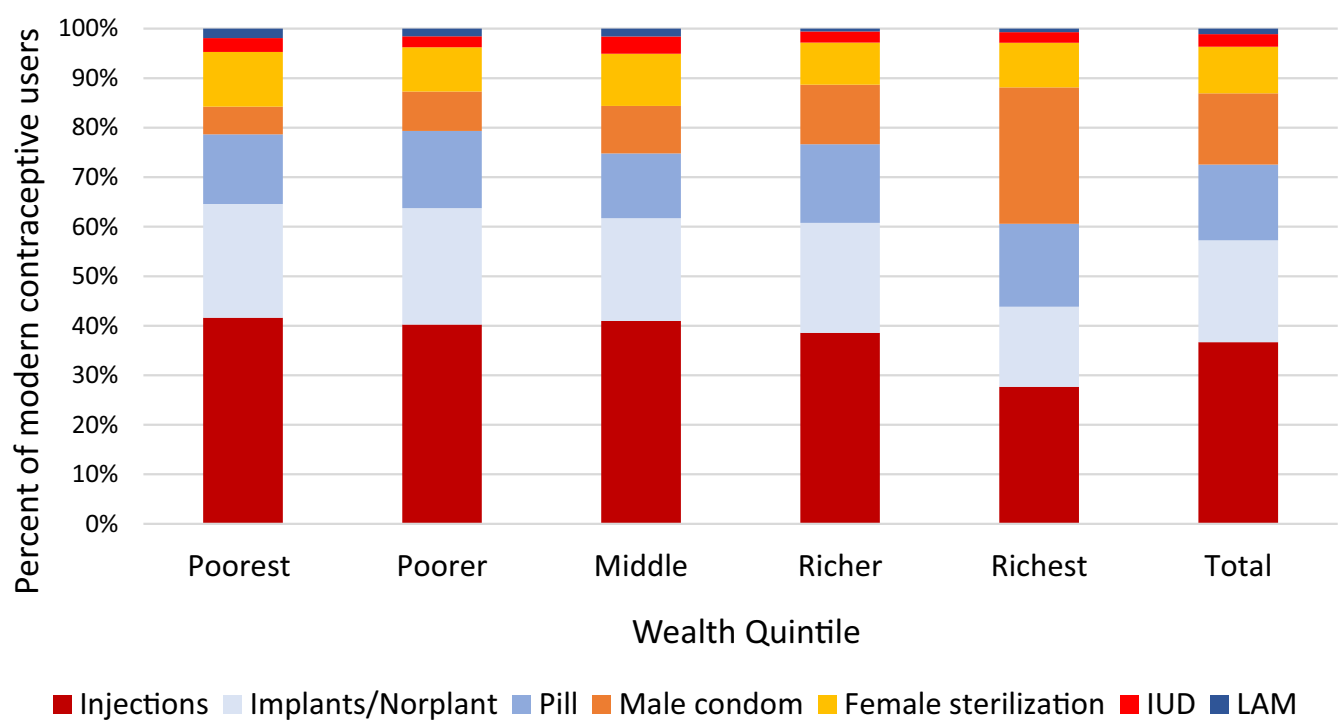

Fig. 1 Method mix among modern contraceptive method users in Tanzania 2015-2016 Demographic Health Survey (unweighted $n=3187$ )

methods for the four poorest wealth quintiles, but were the source for less than $40 \%$ of methods in the richest quintile (Fig. 2). Across all wealth quintiles, government dispensaries were the most common source of the current modern contraceptive method, serving as the source for one-third of current methods. Use of government dispensaries declined across wealth quintiles, ranging from the source of over half of current methods in the poorest quintile to approximately one-tenth in the richest quintile. Government health centers were the source for one-eighth of current methods in the total sample, which was relatively consistent across wealth quintiles. Use of private facilities increased with greater wealth, but served as the source for less than one-tenth of current methods in each wealth quintile. Pharmacies and the composite "other" category were most common in the richest quintile.

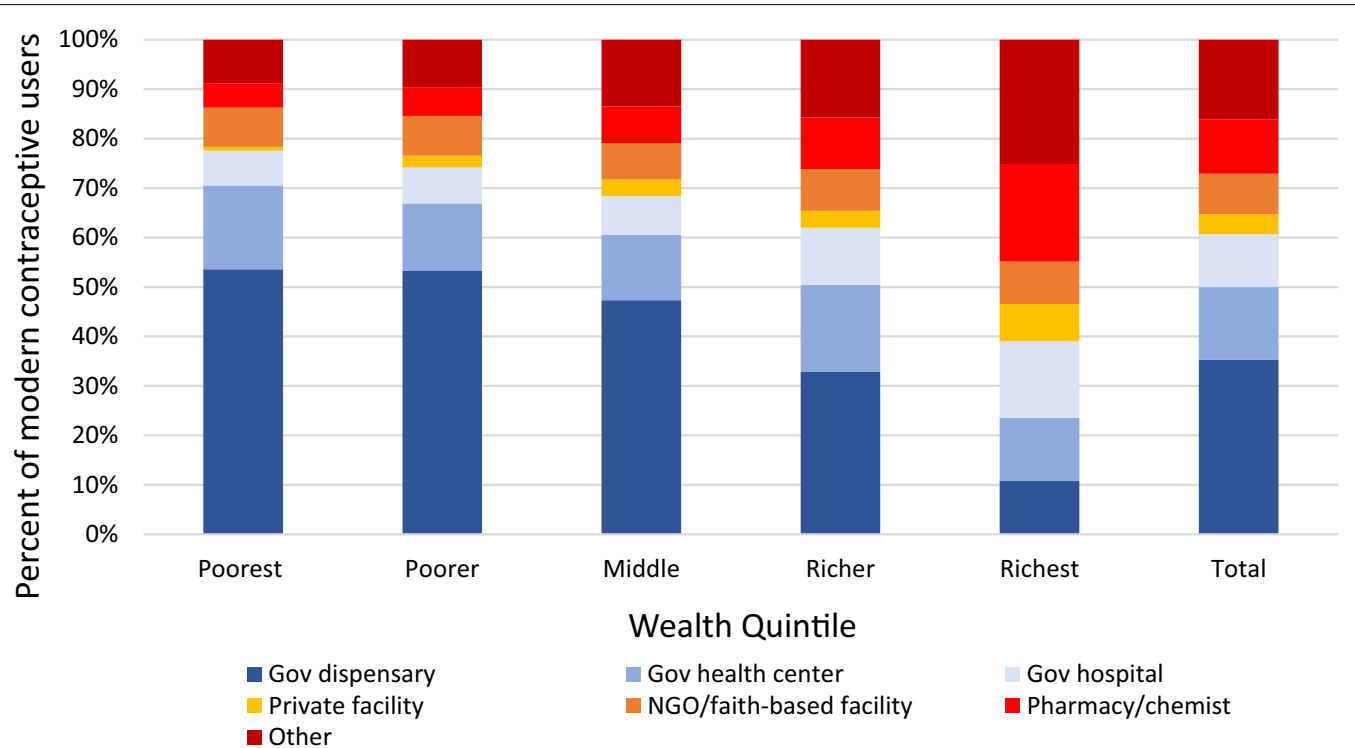

Fig. 2 Facility type visited for family planning by wealth quintile among modern contraceptive method users in Tanzania 2015-2016 Demographic Health Survey (unweighted $n=3187$ ) 
Government dispensaries were the most common source for injectable and implant users in the four poorest wealth quintiles, followed by government health centers (Fig. 3). Injectable and implant users in the richest quintile had the broadest range of sources, with each source accounting for less than one-third of all sources for the current method.

\section{Free family planning at public sector facilities}

Current users of the IUD, injectable, implant, pill and male condom reported whether they paid for their current method, and if so, how much. Averaged across the three types of public facilities, $85 \%$ of FP users who visited a public facility reported that they received free FP (Table 1). This proportion varied across public facility type, with government hospitals reported to provide the greatest proportion of free FP (94\%), followed by government dispensaries $(84 \%)$, and government health centers (83\%). Free FP provision varied by method type, ranging from $78 \%$ of injectable users and $89 \%$ of pill users reporting free FP to $98 \%$ of IUD users reporting free FP at all public sector facilities. Across wealth quintiles, education, and age, the proportion reporting free FP was high, with no discernable pattern suggesting an association between any of these characteristics and the likelihood of being asked to pay for FP.

The proportion of method users reporting free FP was lowest among injectable users who visited government dispensaries; there, just three out of four women reported free FP (74\%). At government dispensaries, approximately nine out of ten pill users and condom users reported free FP (88\% and 90\%, respectively). Similarly, only eight out of ten injectable and implant users reported free FP at government health centers ( $82 \%$ and $80 \%$, respectively).

\section{Payment for injectable and implant at public and private sector facilities}

As shown in Table 1, 78\% of injectable users and $90 \%$ of implant users who visited a public sector facility reported free FP. Among injectable users reporting non-zero payment for their current method, the mean cost for an injectable at a public sector facility was TSh 1420 (approximately 0.61 USD), and at a private sector facility the mean cost was TSh 1930 (approximately 0.83 USD) (Table 2). Among implant users reporting non-zero payment for their current method, the mean cost for an implant at a public sector facility was TSh 4127 (approximately 1.78 USD), and at a private sector facility the mean cost was TSh 6194 (approximately 2.68 USD). Small sample sizes prevented the analysis of cost by sociodemographic characteristics.
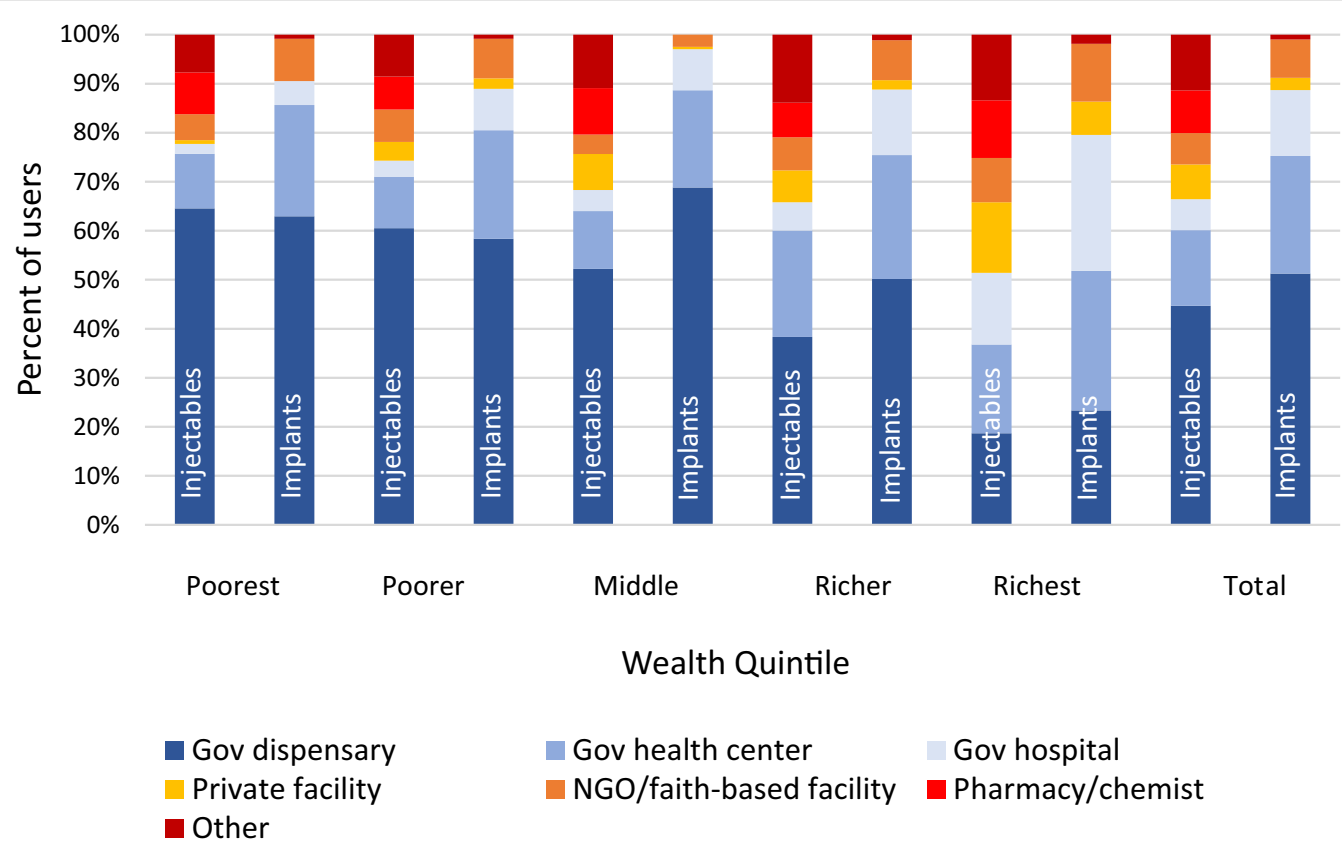

Fig. 3 Provider type visited by wealth quintile among users of injectables and implants in Tanzania 2015-2016 Demographic Health Survey (unweighted $n=1857$ ) 
Table 1 Proportion of modern contraceptive method users reporting free family planning by public sector provider type

\begin{tabular}{|c|c|c|c|c|}
\hline & $\begin{array}{l}\text { Government hospital } \\
\text { (unweighted } n=214 ; \\
\text { weighted } n=220.3 \text { ) }\end{array}$ & $\begin{array}{l}\text { Government health center } \\
\text { (unweighted } n=424 \\
\text { weighted } n=440.7 \text { ) }\end{array}$ & $\begin{array}{l}\text { Government dispensary } \\
\text { (unweighted } n=1141 \\
\text { weighted } n=1174.0 \text { ) }\end{array}$ & $\begin{array}{l}\text { Total public (unweighted } \\
n=1779 \text { weighted } \\
n=1835.0 \text { ) }\end{array}$ \\
\hline Overall (95\% Cl) & $93.7(90.3,97.2)$ & $82.9(78.1,87.7)$ & $83.5(79.9,87.2)$ & $84.6(81.9,87.3)$ \\
\hline \multicolumn{5}{|l|}{ Modern method } \\
\hline Injectable & $92.6(86.4,98.8)$ & $81.7(74.2,89.3)$ & $74.2(67.9,80.5)$ & $77.6(72.7,82.5)$ \\
\hline Implant & $93.4(88.4,98.4)$ & $80.3(72.8,87.8)$ & $94.1(90.7,97.6)$ & $90.3(87.3,93.2)$ \\
\hline Pill & $92.9(79.3,100.0)$ & $91.2(80.1,100.0)$ & $87.8(81.7,93.8)$ & $89.0(84.0,94.0)$ \\
\hline Condom & $100.0(100.0,100.0)$ & $100.0(100.0,100.0)$ & $90.2(78.6,100.0)$ & $93.9(86.5,100.0)$ \\
\hline IUD & $100.0(100.0,100.0)$ & $94.5(86.4,100.0)$ & $100.0(100.0,100.0)$ & $98.0(95.1,100.0)$ \\
\hline \multicolumn{5}{|l|}{ Wealth quintile } \\
\hline Poorest & $100.0(100.0,100.0)$ & $80.5(67.0,94.0)$ & $81.2(72.8,89.6)$ & $81.7(78.8,88.7)$ \\
\hline Poorer & $90.4(78.1,100.0)$ & $94.6(89.5,99.8)$ & $87.1(81.9,92.3)$ & $88.6(84.3,92.9)$ \\
\hline Middle & $95.7(89.6,100.0)$ & $79.5(65.8,93.3)$ & $78.2(72.1,84.3)$ & $79.8(74.3,85.3)$ \\
\hline Richer & $91.5(82.4,100.0)$ & $85.9(78.3,93.5)$ & $86.2(81.1,91.3)$ & $86.8(83.0,90.5)$ \\
\hline Richest & $94.6(89.7,99.5)$ & $76.0(65.2,87.7)$ & $88.1(79.9,96.3)$ & $85.7(80.8,90.6)$ \\
\hline \multicolumn{5}{|l|}{ Educational attainment } \\
\hline No education & $87.1(69.3,100.0)$ & $84.5(72.1,96.9)$ & $78.2(70.7,85.7)$ & $80.1(73.9,86.2)$ \\
\hline Primary & $93.4(88.5,98.3)$ & $86.0(80.8,91.1)$ & $84.4(80.6,88.3)$ & $85.7(82.7,88.7)$ \\
\hline Secondary or higher & $96.4(92.2,100.0)$ & $69.1(54.8,83.5)$ & $85.6(78.5,92.7)$ & $83.8(78.2,89.5)$ \\
\hline \multicolumn{5}{|l|}{ Age group (years) } \\
\hline$<30$ & $94.0(89.6,98.4)$ & $78.3(70.4,86.2)$ & $83.0(78.2,87.7)$ & $83.3(79.6,86.9)$ \\
\hline $30+$ & $93.3(87.5,99.2)$ & $88.0(81.7,94.2)$ & $84.1(80.0,88.4)$ & $86.1(82.8,89.3)$ \\
\hline
\end{tabular}

IUD intrauterine device

Table 2 Amount paid for current contraceptive method among injectable and implant users who reported non-zero payment

\begin{tabular}{|c|c|c|}
\hline & Total public sector & Total private sector \\
\hline \multicolumn{3}{|l|}{ Injectable } \\
\hline N & 157 & 229 \\
\hline Mean cost & 1420 (TSh) & 1930 (TSh) \\
\hline Minimum & 100 (TSh) & 100 (TSh) \\
\hline 25th percentile & 414 (TSh) & 1347 (TSh) \\
\hline Median & 1329 (TSh) & 1690 (TSh) \\
\hline 75th percentile & 1855 (TSh) & 1935 (TSh) \\
\hline Maximum & 1500 (TSh) & 10,000 (TSh) \\
\hline \multicolumn{3}{|l|}{ Implant } \\
\hline N & 55 & 31 \\
\hline Mean cost & 4127 (TSh) & 6194 (TSh) \\
\hline Minimum & 500 (TSh) & 1000 (TSh) \\
\hline 25th percentile & 1758 (TSh) & 2688 (TSh) \\
\hline Median & 2406 (TSh) & 4250 (TSh) \\
\hline 75th percentile & 3850 (TSh) & 7536 (TSh) \\
\hline Maximum & 20,000 (TSh) & 22,000 (TSh) \\
\hline
\end{tabular}

TSh Tanzanian Shilling

\section{Discussion}

In our analysis of 2015-2016 Tanzania DHS data, we found that the vast majority of modern FP users, approximately 85\%, reported free FP at public sector facilities. In the four poorest wealth quintiles, public facilities (government hospitals, government health centers, and government dispensaries) were the source for the majority of current contraceptive methods. In all but the richest wealth quintile, injections and implants were the most commonly used modern FP methods. These findings suggest that most providers within public sector facilities in Tanzania are adhering to enacted policies, which stipulate that FP methods and services should be provided for free at public facilities [6,7]. These findings contrast with those presented by Radovich and colleagues in their analysis of 2014 Kenya DHS data, in which they found that only half of public sector FP users reported that they obtained their method for free despite policies stating that FP methods should be provided for free at public sector facilities [10].

However, implementation of this important policy can still be improved as we found that $22 \%$ of injectable users and $10 \%$ of implant users who visited public facilities reported payment for their current method at a public sector facility. At government dispensaries, one out of every six women reported informal payments for FP methods and/or services. Furthermore, one in every four women who obtained an injectable at a government dispensary was asked for informal payments. These findings 
are especially meaningful, because government dispensaries are the most popular source and implants and injectables are the most popular methods among women in the lowest wealth quintile.

It may be that informal payments arise, because providers are targeting particular patients (e.g., women with low socioeconomic status); however, it may also be that providers at particular facility types are more likely to leverage informal payments, regardless of patient demographics; for example, providers working at government dispensaries may be more likely to be located in a remote area with limited supervision and/or be the sole healthcare provider at their facility, both of which may facilitate solicitation of unsanctioned informal payments. Delineating between these possibilities is outside the scope of the present analysis, but should be a focus of future work examining the etiology of informal payments for FP.

The informal payments reported for injectables at public facilities may be prohibitive for women living around and below the poverty line. In 2018, 14 million people lived below the Tanzanian poverty line of TSh 49,320 per adult per month (about 21 USD) and 26 million (approximately $49 \%$ of the population in Tanzania) lived below the international poverty line of 1.90 USD per person per day [21]. Among those currently using injectables who paid for their method at a public sector facility, the mean cost was TSh 1420 , or approximately 0.61 USD. Though this cost may seem trivial to people not living in poverty, for millions of women in Tanzania, an informal payment of 0.61 USD for an injectable would be a challenging sum to procure.

Demand for and use of implants has increased rapidly in many countries in sub-Saharan Africa over the last decade [22]. In this analysis, we found that, among those who paid for their current method at a public sector facility, the mean informal payment for implants was TSh 4127 (approximately 1.78 USD), which is 3 times the mean informal payment for injectables among those who reported paying any amount for FP at a public facility. This informal payment may be prohibitive for many women. Thus, it is possible that informal payments for implants might be suppressing the true demand for this highly effective method in Tanzania.

Provider demand of informal payments for perinatal healthcare is common in many countries around the world and some studies have focused on their impact on sexual and reproductive health services [10, 12, 23-30]. The frequency of informal payments differs substantially by country, ranging from 3\% in Peru to $96 \%$ in Pakistan [12]. While informal payments are quite common across South Asian countries, payment frequency varies widely by country in East Asia, Latin America, and Eastern Europe; in sub-Saharan Africa, evidence from studies in
Uganda, Mozambique and Ethiopia suggests that informal payments to public sector providers are common [12]. The size of these informal payments varies, but can add up to a formidable sum, especially for patients with low socioeconomic status and for those who are charged informal payments at several points while accessing care. Tragically, knowledge that providers may solicit informal payments when patients seek care may prevent care seeking altogether, particularly for patients who have few financial resources $[23,25,29,30]$.

The literature suggests several reasons for informal payments in public sector facilities, which may be relevant to the Tanzanian context. Tumlinson and colleagues analyzed in-depth semi-structured interviews with 20 public and private sector reproductive healthcare workers in Kenya, and found that providers cited low public sector wages as a chief reason that providers ask patients for informal payments [18]. Providers reported that senior staff often worked together to solicit informal payments and explained that patients might be charged informal payments, because they do not know which services should be provided free of charge. These findings suggest both individual-level and structural-level levers for reducing the solicitation of informal payments at public sector facilities, including educating patients about the free provision of FP at public facilities in Tanzania and fairly compensating public sector healthcare workers for their labor. Salaries of providers in public sector facilities in Tanzania are typically standardized within specific job "groups," which, in theory, are based on education and years of experience (though, in practice, promotions can be delayed). In addition, wages may fail to keep pace with inflation and there may be variation across facilities or regions with regard to timely payment of wages (In an email from D. Onyango, MD in January 2022).

There is limited evidence evaluating strategies to reduce informal payments for family planning and reproductive health services, though social accountability approaches have emerged as promising strategies [31, 32]. One social accountability approach, called the Community Score Card, was implemented in Malawi and found to increase client satisfaction, contraceptive use, and service delivery compared to communities who did not receive the intervention, but the intervention's impact on informal payments was not assessed [33]. Another social accountability intervention was designed to decrease demand for informal payments for maternal health care and implemented in India. The intervention appeared to increase the empowerment and knowledge of participating community members and anecdotal evidence suggested a decrease in demands for informal payments [17, 34].

Though informal payments may be less of a problem in Tanzania than in neighboring countries, progress is 
still needed to eliminate all informal fees at public sector facilities in Tanzania. Further research should investigate the reasons that informal payments are solicited in public sector facilities, especially government dispensaries, and identify methods for reducing these fees to ensure that the most vulnerable populations have access to the FP services needed to achieve their reproductive goals.

\section{Strengths}

This study uses nationally representative data to investigate informal payments for FP in Tanzania. We use existing data to study an important topic with critical implications for FP access.

\section{Limitations}

Our investigation of informal payments for modern contraceptives was limited by sample size constraints. Because a minority of women reported paying any amount at public or private facilities for implants or injectables, we were not able to assess whether payment amount varied by sociodemographic factors, such as education, age, or wealth. In addition, these existing data do not allow us to assess the proportion of women who were unable to pay informal payments and, therefore, left the facility without a method of contraception. Given evidence suggesting women with fewer resources may be more likely to be asked for informal payments [17], new indicators are needed to track this equity concern. We are also unable to ascertain whether some FP clients were able to avoid informal payments by insisting on free services or switching to a different provider or different public sector facility. These are important areas for future research.

\section{Conclusion}

Voluntary, safe family planning is critical for the health of women and children. Tanzania's contraceptive prevalence rate among married women is just $38 \%$ and disparities in FP use make women who are least educated, poorest, and unmarried and sexually active particularly vulnerable to unintended pregnancy [3]. Ensuring access to FP for all who want it requires the elimination of barriers to FP, and concerns about costs of FP are a known barrier [6]. Tanzanian policies dictate that FP methods and services are provided for free at public sector facilities, but to our knowledge, no published studies investigate the implementation of this policy $[6,7]$. Our findings indicate that most modern FP users report receiving their method for free at public sector facilities in Tanzania. Still, some implant and injectable users report informal payments for their methods at public facilities, suggesting that implementation of FP cost initiatives in Tanzania could be improved. Future research should investigate whether informal payments prevent women from obtaining their desired FP method and characterize how informal payments are leveraged at government dispensaries and health centers to inform interventions.

\section{Abbreviations}

FP: Family planning; Cl: Confidence interval; TSh: Tanzanian Shillings; USD: United States Dollars; DHS: Demographic Health Survey; LMICs: Low- and middle-income countries; IUD: Intrauterine device; LAM: Lactational Amenorrhea Method.

\section{Acknowledgements \\ Not applicable.}

\section{Authors' contributions}

CEB and KT conceptualized the paper. CEB designed and conducted the analysis, and wrote the first draft. DO made substantial contributions to the interpretation of the data, and substantively revised and edited the manuscript. KT supported the study design and analysis, and revised and edited the manuscript. All authors read and approved the final manuscript.

\section{Funding}

CEB was supported by the Population Research Infrastructure Program (P2C HD050924) and the National Institute of Child Health and Human Development (NICHD) of the National Institutes of Health $(\mathrm{NIH})$ under the Population Research Training grant (T32 HD007168) awarded to the Carolina Population Center at The University of North Carolina at Chapel Hill. CEB was additionally supported by the University of North Carolina Royster Society of Fellows. KT was supported in part by a career development grant (R00 HD086270) and an infrastructure grant for population research (P2C HD047879) awarded to the Carolina Population Center at the University of North Carolina at Chapel Hill, both of which were awarded by the NICHD of the NIH. The contents of this article are solely the responsibility of the authors and do not necessarily represent the official views of the $\mathrm{NIH} / \mathrm{NICHD}$.

\section{Availability of data and materials}

The Demographic and Health Survey data used in this study are available from the Demographic and Health Survey Program, [https://dhsprogram.com/ data/].

\section{Declarations}

Ethics approval and consent to participate

This study was reviewed by the Office of Human Research Ethics at the University of North Carolina at Chapel Hill and was determined to be exempt from further review.

\section{Consent for publication}

Not applicable.

\section{Competing interests}

The authors declare that they have no competing interests.

\section{Author details}

${ }^{1}$ Carolina Population Center, University of North Carolina at Chapel Hill, NC, Chapel Hill, United States of America. ${ }^{2}$ Department of Maternal and Child Health, Gillings School of Global Public Health, University of North Carolina at Chapel Hill, NC, Chapel Hill, United States of America. ${ }^{3}$ Kisumu County Department of Health, P.O. BOX 3670, Kisumu 40100, Kenya. ${ }^{4}$ Utrecht University, Utrecht, The Netherlands. ${ }^{5}$ Institute of Tropical Medicine, Antwerp, Belgium.

Received: 7 October 2021 Accepted: 18 January 2022

Published online: 29 January 2022 


\section{References}

1. Cleland J, Conde-Agudelo A, Peterson H, Ross J, Tsui A. Contraception and health. Lancet. 2012:380:149-56.

2. Starbird E, Norton M, Marcus R. Investing in family planning: key to achieving the sustainable development goals. Glob Health Sci Pract. 2016;4:191-210

3. (2019) Family Planning Data Sheet. https://www.prb.org/wp-content/ uploads/2019/09/fp-data-sheet-2019.pdf.

4. Tanzania. In: Family Planning 2020. https://www.familyplanning2020.org/ tanzania. Accessed 14 Apr 2021.

5. Ministry of Health, Community Development, Gender, Elderly and Children-MoHCDGEC/Tanzania Mainland, Ministry of Health-MoH/Zanzibar, National Bureau of Statistics - NBS/Tanzania, Office of Chief Government Statistician-OCGS/Zanzibar, and ICF (2016) Tanzania Demographic and Health Survey and Malaria Indicator Survey (TDHS-MIS) 2015-16. Dar es Salaam/Tanzania: MoHCDGEC, MoH, NBS, OCGS, and ICF.

6. Ministry of Health and Social Welfare (2010) The National Family Planning Costed Implementation Program: 2010-2015.

7. Ministry of Health and Social Welfare (2013) National Family Planning Guidelines and Standards.

8. Ministry of Health (2016) Kenya Reproductive, Maternal, Newborn, Child and Adolescent Health (RMNCAH) Investment Framework.

9. Ministry of Public Health and Sanitation (2008) The Second National Health Sector Strategic Plan of Kenya: 2008-2012.

10. Radovich E, Dennis ML, Barasa E, Cavallaro FL, Wong KLM, Borghi J, Lynch CA, Lyons-Amos M, Abuya T, Benova L. Who pays and how much? A cross-sectional study of out-of-pocket payment for modern contraception in Kenya. BMJ Open. 2019;9:1-11.

11. Chuma J, Maina T. Free maternal care and removal of user fees at primarylevel facilities in Kenya: monitoring the implementation and impactbaseline report. 2013

12. Lewis M. Informal payments and the financing of health care in developing and transition countries. Health Aff. 2007;26:984-97.

13. Ensor T. Informal payments for health care in transition economies. Soc Sci Med. 2004;58:237-46.

14. Gaal P, Belli PC, McKee M, Szócska M. Informal payments for health care: definitions, distinctions, and dilemmas. J Health Polit Policy Law. 2006;31:251-93.

15. Balabanova D, Mckee M. Understanding informal payments for health care: the example of Bulgaria. Health Policy. 2002. https://doi.org/10. 1016/S0168-8510(02)00035-0.

16. Mæstad O, Mwisongo A. Informal payments and the quality of health care: mechanisms revealed by Tanzanian health workers. Health Policy. 2011;99:107-15.

17. Schaaf M, Topp SM. A critical interpretive synthesis of informal payments in maternal health care. Health Policy Plan. 2019;34:216-29.

18. Tumlinson K, Gichane MW, Curtis SL. "If the big fish are doing it then why not me down here?": informal fee payments and reproductive health care provider motivation in Kenya. Stud Fam Plann. 2020;51:33-50.

19. ICF. Demographic and Health Surveys Standard Recode Manual for DHS7. The Demographic and Health Surveys Program. Rockville, Maryland, U.S.A.: ICF; 2008

20. Ministry of Health, Community Development, Gender, Elderly and Children-MoHCDGEC/Tanzania Mainland, Ministry of Health-MoH/Zanzibar, National Bureau of Statistics-NBS/Tanzania, Office of Chief Government Statistician-OCGS/Zanzibar, and ICF (2016) Tanzania Demographic and Health Survey and Malaria Indicator Survey 2015-2016. TZIR7BFL.DAT. Dar es Salaam, Tanzania: MoHCDGEC, MoH, NBS, OCGS, and ICF [Producers]. ICF [Distributor], 2016. http://dhsprogram.com/pubs/pdf/FR321/ FR321.pdf.

21. World Bank Group. Tanzania mainland poverty assessment: executive summary. 2019.

22. Jacobstein R. Liftoff: the blossoming of contraceptive implant use in Africa. Glob Health Sci Pract. 2018:6:17-39.

23. Afsana K. The tremendous cost of seeking hospital obstetric care in Bangladesh. Reprod Health Matters. 2004;12:171-80.

24. Pieterse $\mathrm{P}$, Lodge T. When free healthcare is not free. Corruption and mistrust in Sierra Leone's primary healthcare system immediately prior to the Ebola outbreak. Int Health. 2015;7:400-4.
25. Colombini M, Rechel B, Mayhew SH. Access of Roma to sexual and reproductive health services: qualitative findings from Albania, Bulgaria and Macedonia. Glob Public Health. 2012;7:522-34

26. Kruk ME, Mbaruku G, Rockers PC, Galea S. User fee exemptions are not enough: out-of-pocket payments for 'free' delivery services in rural Tanzania. Trop Med Int Health. 2008;13:1442-51

27. Vian T, Feeley FG, Domente S, Negruta A, Matei A, Habicht J. Barriers to universal health coverage in Republic of Moldova: a policy analysis of formal and informal out-of-pocket payments. BMC Health Serv Res. 2015;15:319.

28. Tumlinson K, Britton LE, Williams CR, Wambua DM, Otieno Onyango D. Informal payments for family planning: prevalence and perspectives of women, providers, and health sector key informants in western Kenya. Sex Reprod Health Matters. 2021. https://doi.org/10.1080/26410397.2021. 1970958.

29. Tumlinson K, Speizer IS, Archer LH, Behets F. Simulated clients reveal factors that may limit contraceptive use in Kisumu, Kenya. Glob Health Sci Pract. 2013;1:407-16.

30. Larsson EC, Thorson A, Nsabagasani X, Namusoko S, Popenoe R, Ekström AM. Mistrust in marriage - reasons why men do not accept couple HIV testing during antenatal care — a qualitative study in eastern Uganda. BMC Public Health. 2010;10:769.

31. Boydell V, Keesbury J. Social accountability: what are the lessons for improving family planning and reproductive health programs?: A review of the literature. Washington D.C. 2014.

32. McGinn E, Lipsky A. Social accountability: a primer for civil society organizations working in family planning and reproductive health. Washington D.C. 2015.

33. Gullo S, Galavotti C, Sebert Kuhlmann A, Msiska T, Hastings P, Marti CN. Effects of a social accountability approach, CARE's Community Score Card, on reproductive health-related outcomes in Malawi: a clusterrandomized controlled evaluation. PLoS ONE. 2017;12: e0171316.

34. Dasgupta J, Sandhya YK, Lobis S, Verma P. Using technology to claim rights to free maternal health care: lessons about impact from the my health, my voice pilot project in India. Health Hum Rights. 2015:17:135-47.

\section{Publisher's Note}

Springer Nature remains neutral with regard to jurisdictional claims in published maps and institutional affiliations.

Ready to submit your research? Choose BMC and benefit from

- fast, convenient online submission

- thorough peer review by experienced researchers in your field

- rapid publication on acceptance

- support for research data, including large and complex data types

- gold Open Access which fosters wider collaboration and increased citations

- maximum visibility for your research: over $100 \mathrm{M}$ website views per year

At BMC, research is always in progress.

Learn more biomedcentral.com/submissions 